\section{The scorbutic story}

\section{John Rivers}

The History of Scurvy and Vitamin C. By Kenneth J. Carpenter. Cambridge University Press: 1986. Pp.288. f27.50, $\$ 39.50$.

JoHn Le Carré might have told this story better, but I doubt that he could have produced a better book. Like Kenneth Carpenter, Le Carré could have told the tortuous tale of 400 years of medical misunderstanding of scurvy, leading along false trails, down blind alleys and round and round in circles. And Le Carré would if anything have made the reader more aware that, because scurvy was a disease that particularly afflicted armies and especially navies, we are dealing not only with medicine but with grand strategy. The real difference in treatment would come in the last chapter where, the history of scurvy having become the story of the discovery of vitamin $\mathrm{C}$, the author presents a scientific retrospect in which centuries of confusion are put beneath the spotlight of modern knowledge. If Le Carré had unleashed Smiley on these problems, the dénouement would have been far more slick.

Professor Carpenter, however, has been too honest and thorough in his analysis to pretend that all the questions are now resolved. Some, of course, are: the mystery of why the Esquimaux didn't get scurvy, despite eating no vegetables and fruit, is explained by the ascorbic acid content of fresh raw meat. But other problems remain perplexing even today. Why, for example, were so many cases of shipboard scurvy apparently cured by the once-favoured mixture of vinegar and potassium nitrate? The mixture contains no vitamin C; so was it lies, self deception, a placebo effect on an unprecedented scale or something we don't yet understand. The problem is left hanging.

Some certainties fall apart beneath Carpenter's critical analysis. James Lind, for example, doesn't seem anywhere near so epoch-making when Carpenter has finished with him. On the bicentennial of the publication of $A$ Treatise on Scurvy, Lind was beatified by scientists as the inventor of the clinical trial and the first truly modern nutritionist. But the Lind to whom Professor Carpenter draws our attention ends up more human, someone who despite his studies on lemon juice as an antiscorbutic believed that cold and damp air actually caused scurvy. By the end of his life, it seems, Lind was a deeply pessimistic man, doubting his own observations which he was unable to replicate in studies at Haslar hospital, where even the controls mysteriously recovered, and concluding in the third edition of his Treatise that "enlarged experience must ever evince the fallacy of all positive assertions in the healing art".

Captain James Cook, too, is seen in a more perceptive light. Cook's circumnavigation of the world was free from scurvy not simply because he used Lind's prescribed lemon juice. He took almost every antiscorbutic that anyone recommended, with the result that the trip provided no test of Lind's hypothesis. Indeed, says Carpenter, Cook may have delayed the general introduction of lemon juice as a prophylactic because every theorist drew sustenance for their pet idea from his provisioning strategy; the award of the Royal Society's Copley medal to Cook, for his success in avoiding scurvy, seems to have been supported by Sir John Pringle, the President of the Royal Society, because he regarded Cook's triumph as evidence in favour of his favourite hypothesis that malted grain was the preventative of choice.

Such re-evaluations are the result of careful research on Professor Carpenter's part, not idle iconoclasticism. Indeed, in springing to the defence of the Admiralty, Carpenter attacks the iconoclasticism of others. It is often held that the continuance of scurvy in the British navies during the nineteenth century was the result of the Admiralty's penny-pinching decision to abandon lemon juice in favour of lime juice from the West Indian colonies which, though cheaper, had no vitamin C activity. The truth is not so simple. Not only are limes a good source of vitamin C, but the words lemon and lime were used interchangeably and it is not always possible to be sure what was being done. Carpenter suggests that the ineffectiveness of lime juice may have been due to catalysis of the oxidation of the ascorbic acid by copper in the stills and vessels used to concentrate the juice, compounded by overlong storage. The Admiralty was doing its best; it was the scientists who were wrong.

This is an extremely detailed book, and at times I wondered whether Carpenter should not have begun with the modern knowledge of vitamin $\mathrm{C}$ to aid the reader in interpreting the sheer mass of erroneous evidence and theory that runs down the centuries: a sort of answers first, questions afterwards strategy. But the lack of certainty in the final clarification shows that we don't yet have all the answers, and some questions must just remain. That alone makes the book worthwhile, as well as delightful to read, and a volume that will inform and entertain both historians and scientists - and, indeed, anyone who likes a good mystery story, even if it isn't written by Le Carré.

John Rivers is a Senior Lecturer in the Department of Human Nutrition, London School of Hygiene and Tropical Medicine, Keppel Street, London WCIE $7 H T$, UK.

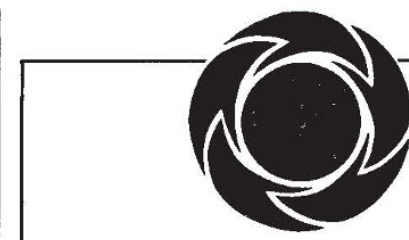

\section{INSTITUTE OF TERRESTRIAL ECOLOGY}

Landscape changes in Britain C.J. Barr, C.B. Benefield, R.G.H. Bunce,

H.A. Ridsdale \&

M. Whittaker

A largely visual presentation of results from 2 landscape surveys of Great Britain.

28pp, $0904282953 £ \mathbf{3 . 0 0}$

\section{Pollution in Cumbria}

P. Ineson

Proceedings of a symposium concerned with acid rain, radioactivity, industrial and agricultural pollution.

92pp, $0904282961 £ 5.75$

\section{Coast dune management guide}

D.S. Ranwell \& R. Boar

How to use vegetation for coast protection activities, with particular reference to sand dunes.

$105 p p, 0904282937 £ 6.00$

\section{Distribution and status of bats in Europe}

R.E. Stebbings \& F. Griffith

31 species are described under the following headings:

distribution, habitat,

population, threats,

conservation measures,

bibliography.

142pp. $0904282945 £ 5.00$

\section{Full list from}

Publications Section

Merlewood Research Station

Grange-over-Sands

Cumbria LA11 6JU, UK

Many earlier titles now reduced in price.

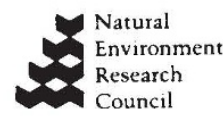

